\section{Delayed immune mediated adverse effects to hyaluronic acid fillers: report of five cases and review of the literature}

\author{
Ora Bitterman-Deutsch, ${ }^{1,2}$ \\ Leonid Kogan, ${ }^{1,3}$ Faris Nasser ${ }^{1,4}$ \\ ${ }^{1}$ Faculty of Medicine in the Galilee, Bar \\ Ilan University, Safed; '2Dermatology \\ Clinic, ${ }^{3}$ Department of Plastic Surgery, \\ ${ }^{4}$ Department of Internal Medicine E, \\ Galilee Medical Center, Nahariya, Israel
}

\section{Abstract}

Hyaluronic acid (HA) fillers in cosmetic medicine have been considered relatively safe, though fillers used in European countries and throughout the world are not necessarily approved by the Food and Drug Administration. As their use continues to expand worldwide, physicians in a wide range of medical specialties are authorized to perform HA injections, including general medicine practitioners and even dentists. An increasing number of reports have appeared regarding side effects to these products. It is now known that reactions to Hyaluronic acid are related not only to technical faults of the injections, but also to immune responses, including delayed hypersensitivity and granulomatous reactions. Herein, we describe five cases treated by a variety of treatment modalities, all with delayed reactions to different brands of hyaluronic acid fillers. As there is currently no standardization of treatment options of adverse effects, these cases accentuate the debate regarding the approach to the individual patient and the possible need for pre-testing in patients with an atopic tendency.

\section{Introduction}

In recent years rejuvenation of the skin with fillers has become one of the most common procedures in aesthetic medicine, performed by physicians in a wide range of medical specialties, including family physicians and even dentists. ${ }^{1}$ Hyaluronic acid (HA) fillers for soft tissue augmentation were introduced into the market in the late 90s (1996 in Europe, and 1999 in the USA). Since then they have been considered one of the safest substances available, and the highest in demand. ${ }^{2}$ Their use has extended from only facial treatments to treatments of the neck, limbs and breast. ${ }^{3}$

In the European Union (EU), there is a much wider range of approved HA products than in the U.S (where only Restylane and Juvederm are Food and Drug Administrationapproved). The lower cost of these products and the broader spectrum of HA cohesivity have led to their widespread use. ${ }^{4}$

Until 2010 relatively few adverse reactions were described and most were considered procedure-related. Nonetheless, there are recent reports of hypersensitivity reactions to HA or one of the other gel components. ${ }^{5-9}$

We herein describe five cases treated by a variety of treatment modalities, all with delayed reactions to different brands of Hyaluronic acid fillers.

Our case series adds to these reports regarding the types of immune responses causing skin reactions to HA fillers.

\section{Case Report}

All five patients were female, age range 2956 , median age 46.5 years (see Table 1 for patients' characteristics). Three patients had atopic disposition: allergy to drugs (patient 1: dipirone and patient 2: penicillin) and asthma (patient 4). Two patients (patients 3 and 4) were injected with varioderm (one to the glabella area and lips and the other to the back of the hands), one with resylane to naso-labial folds (patient 2) and one with matriderm/matridur to naso-labial folds and zygomas (patient 5).

All patients but one (patient 5) had previous experience with botulinum toxin injections. patient 1 was treated simultaneously with varioderm injections and botulinum toxin around glabella and eyes.

Symptoms began after 48 hours in patient 3 (Figure 1A). In patients 2 and 4 reactions occurred after 2 weeks (Figures 1B,C), and in patients 1 and 5 (Figures 1D,E) latency period was 7 months and more than 1.5 year, respectively, after initiation of injection with matriderm/matridur.

Treatment included oral prednisolone (patients 1, 3 and 4), i.v. Hydrocortisone (patient 2), intradermal methylprednisolone acetate (patients 4 and 5) intravenous and oral antibiotics (patients 1, 3 and 5) cephalosporines, amoxycillin, quinolones, antihistamines (chlorphenidramine maleate), and aspiration of nodule (patient 1).

Remission from symptoms was obtained after two weeks (patients 2 and 3), one month (patient 1), and one year (patient 4) and less than 1.5 years in patient 5 who continues to have episodes of asymmetrical edema of the face, responding to steroid treatment (with 3-6 months periods of remission).

Blood tests were performed in just three patients, with normal results except for mild
Correspondence: Ora Bitterman-Deutsch, Dermatology Clinic, Galilee Medical Center, P.O. Box 21, Nahariya, Israel.

Tel.: +972.507887946 - Fax: +972.49107 .

E-mail: docora21@windowslive.com

Key words: delayed adverse effects, hyaluronic acid fillers, treatment, hyaluronidase, allergic mechanism.

Acknowledgements: the authors would like to thank Tobie Kuritsky for assistance in editing and organizing the manuscript.

Contributions: the authors contributed equally.

Conflict of interest: the authors declare no potential conflict of interest.

Received for publication: 5 February 2015. Accepted for publication: 23 March 2015.

This work is licensed under a Creative Commons Attribution NonCommercial 3.0 License (CC BYNC 3.0).

(C) Copyright O. Bitterman-Deutsch et al., 2015 Licensee PAGEPress, Italy

Dermatology Reports 2015; 7:5851

doi:10.4081/dr.2015.5851

Leucocytosis in patient 3 and microcytic anemia in patient 1 .

Ultrasound and CT of the face were performed in patient 1 . Hyperdense collections in the subdermal fat were described. Cytologic examination of aspired material revealed amorphic material, but no bacteriologic growth. Magnetic resonance imaging of the face in patient 5 showed non-specific edema, possibly due to an inflammatory reaction to the injected material.

\section{Discussion}

In the last decade dermal filler implantation has become one of the most popular methods for rejuvenation. ${ }^{10,11} \mathrm{HA}$ belongs to a group of glycosaminoglycans or acid mucopolysaccharides, which are part of the cutaneous dermal ground substance. HA can be obtained from both animal and non-animal origin., ${ }^{2,12,13}$

Theoretically, the risks for immune mediated reactions are minimized when $\mathrm{HA}$ is obtained biosynthetically by bacterial fermentation, due to lack of food allergens, thus is considered safe from transmitting diseases between species. ${ }^{14,15}$

In practice, there is an increasing number of reports of immediate and delayed side effects to these compounds (occurring one week to one year after injections). ${ }^{15-21}$

Apart from the transient, non-allergic, local 
side effects (e.g. slight edema, ecchymoses, hypercorrection and bluish discoloration) due to technical problems during the injections, other more serious long term symptoms (e.g. tender granulomas, edema and indurated nodules) were reported, suggesting an allergic mechanism. ${ }^{6,22}$

Compounds variance may cause these reactions, however an allergic tendency in certain patients undoubtable exacerbates these adverse effects to the infections of hyaluronic fillers. ${ }^{6,13,23}$

These adverse effects, especially those of allergic origin are attributed to the hyaluronin associated protein component in the products and/or the impurities from the bacterial fermentation process, such as contaminated DNA. $^{24-26}$ It has been suggested that glycosaminoglycans act as superantigens (bypassing the normal mechanism of activation of the inflammation process), thus directly activating the immune reactive cells. ${ }^{13,27}$ Infections are rare, mainly caused by herpes simplex and mycobacterium abscessus. ${ }^{1,22,28-32}$

In recent years most of the attention has been drawn to biofilms, an infectious complication due to microorganisms with excretion of an extracellular protective adhesive matrix allowing development of antibiotic-resistant microorganisms. ${ }^{24,26,29,33,34}$

Biofilms cause erythematous nodules, which are considered to be aseptic abscesses. ${ }^{24}$ Recommendations for treatment of these late onset nodules vary, between oral antibiotics, aspiration or nodule biopsy, in order to avoid further sepsis, and/or additional hyaluronidase injections (in order to reduce HA load as the causative agent). A consensus regarding the efficacy of this treatment exists in the presence of residual hyaluronic acid in the tissue. The recommendation is to perform the procedure shortly after the injection (preferably within the first 24 hours). ${ }^{20,35}$

This is also the preferred modality in late onset allergic reactions and vascular complications. ${ }^{32,35,36}$ Our patients were treated with products containing HA in varying concentrations made by different manufacturers..$^{1,25}$

Varioderm Plus (by Adoderm Gmbh, Langenfeld, Germany, since 2008) is a highly cross-linked (18 mg/mL) pyrogen free HA gel of non-animal origin, not FDA-approved. Increased tendency to swelling in the initial phase of administration was noted by Weidman while using the product during a period of two years. ${ }^{37}$

Matridur (CE approved since 2004, not FDA approved) is a mixture of non animal stabilized HA $25 \mathrm{mg} / \mathrm{mL}$ and cross linked HA 25 $\mathrm{mg} / \mathrm{mL}$. Matridex contains cross-linked HA and dextranomers. A few cases of granulomatous reactions to these compounds have been reported. $5,10,38$

The brand name of restylane (by Q-Med AB, Uppsala, Sewden, since 1999, FDA-approved) stands for products made by NAHSA gel - a non-animal HA stabilized with BDDE. The difference between the products (Restylane perlane, Restylane and Sub-Q, etc.) is in the size of the NASHA particles. ${ }^{5}$

These are among the oldest HA products in the market, with vast documentation of all types of hypersensitivity reactions, although granulomatous reactions and systemic manifestations were very rare, ${ }^{17,23,39}$ until recent reports. ${ }^{7,8}$

In our report we described three patients with a known allergic tendency. All had delayed hypersensitivity reactions. ${ }^{20,40}$ Additionally, the site of injection may influence the reaction, as was seen in patient 4 (after injection of varioderm plus to back of hands), who developed a generalized reaction. ${ }^{27,40}$

These observations accentuate the debate whether to perform an intradermal skin test for HA injections prior to treatment. ${ }^{6}$

Our patients had systemic antibiotic and steroid therapy, intradermal steroid injections, and aspiration of nodule, but none had hyaluronidase intradermal treatment.

Another important issue that stands out while reviewing the treatments of our patients is the lack of standardization. Most patients experiencing adverse effects of aesthetic treatments consult their family physician and/or the physician who performed the treatments.

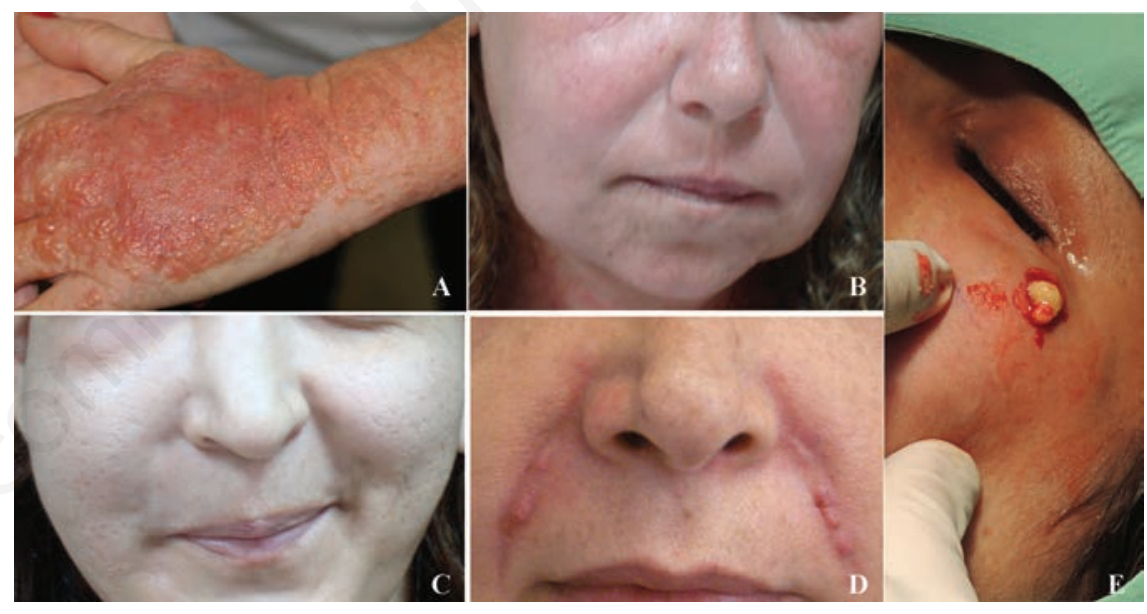

Figure 1. A) patient 3; B) patient 2; C) patient 4; D) patient 1; E) patient 5.

Table 1. Patients' clinical characteristics.

\begin{tabular}{|c|c|c|c|c|c|c|}
\hline Patient & Age & Type of filler & $\begin{array}{l}\text { Latency } \\
\text { (days) }\end{array}$ & Known allergy & Clinical findings & Treatment \\
\hline 1 & 29 & $\begin{array}{l}\text { Matriderm, } \\
\text { matridur }\end{array}$ & 112 & Dypirone & $\begin{array}{c}\text { Asymmetry, } \\
\text { edema, } \\
\text { inflammatory } \\
\text { nodules }\end{array}$ & $\begin{array}{l}\text { Cefalosporines, quinolones, clindamycin, } \\
\text { prednisone, chlorpheniramine-maleateaspiration }\end{array}$ \\
\hline 2 & 49 & $\begin{array}{c}\text { Restylane } \\
\text { perlane botox } \\
\text { (galbella + eyes) }\end{array}$ & 28 & Penicilline & Facial edema & Hydrocortisone Chlorpheniramine-maleate \\
\hline 3 & 52 & $\begin{array}{l}\text { Varioderm, } \\
\text { dysport (glabella) }\end{array}$ & 2 & - & $\begin{array}{l}\text { Inflammatory nodules, } \\
\text { pustules, fever }\end{array}$ & Prednisone, cefamezin, coloplast cream \\
\hline 4 & 56 & Varioderm plus & 14 & Asthma & $\begin{array}{c}\text { Generalized } \\
\text { pruritus, blisters }\end{array}$ & $\begin{array}{c}\text { Prednisone, fexofenadine, saline dressings, } \\
\text { betamethasone cream }\end{array}$ \\
\hline 5 & 42 & Matriderm, matridur & r 365 & - & Inflammatory nodules & Moxypen cefamezin \\
\hline
\end{tabular}


Treatment of the side effects depends on the specialty and skills of these doctors. ${ }^{41}$ Even when patients are hospitalized treatment depends on department policy. There is a necessity for wider understanding of aesthetic procedures in general medicine, as four of our patients required visits to the general emergency room, where the first physician to see them was an internist.

\section{Conclusions}

Based on the wide range of reactions to different products injected (many of which are widely used throughout the world, but are not FDA-approved), and the growing knowledge of the possibility for delayed adverse reactions, patients must be informed of these risks.

Considering practitioners in different medical fields perform these procedures, warrants publication of specific guidelines for treatment of adverse effects, in addition to establishing a protocol for patients with an atopic tendency.

\section{References}

1. Emer J, Waldorf $H$. Injectable neurotoxins and fillers: there is no free lunch. Clin Dermatol 2011;29:678-90.

2. Friedman PM, Mafong EA, Kauvar AN, et al. Safety data of injectable nonanimal stabilized hyaluronic acid gel for soft tissue augmentation. Dermatol Surg 2002;28: 491-4.

3. Dadzie OE, Mahalingam M, Parada M, et al. Adverse cutaneous reactions to soft tissue fillers - a review of the histological features. J Cutan Pathol 2008;35:536-48.

4. Ellis DA, Segall L. Review of non-FDAapproved fillers. Facial Plast Surg Clin North Am 2007;15:239-46.

5. Requena L, Requena C, Christensen L, et al. Adverse reactions to injectable soft tissue fillers. J Am Acad Dermatol 2011;64:134.

6. Hanke CW. Evolution of filler materials in dermatology. J Am Acad Dermatol 2013;68: 858-9.

7. Luebberding S, Alexiades-Armenakas M. Safety of dermal fillers. J Drugs Dermatol 2012;11:1053-8.

8. Gilbert E, Hui A, Waldorf HA. The basic science of dermal fillers: past and present. Part I: background and mechanisms of action. J Drugs Dermatol 2012;11:1059-68.

9. Piacquadio D, Jarcho M, Goltz R. Evaluation of hylan-b gel as a soft tissue augmentation implant material. J Am Acad Dermatol 1997;36:544-9.

10. Massone C, Horn M, Kerl H, et al. Foreign body granuloma due to Matridex injection for cosmetic purposes. Am J Dermatopathol 2009;31:197-9.

11. Al-Shraim M, Jaragh M, Geddie W. Granulomatous reaction to injectable hyluronic acid (Restylane) diagnosed by fine needle biopsy. J Clin Pathol 2007;60:1060-1.

12. Romagnoli M, Belmontesi M. Hyaluronic acid based fillers: theory and practice. Clin Dermatol 2008;26:123-59.

13. Sundaram H, Voigts B, Beer $K$, et al. Comparison of the rheological properties of viscosity and elasticity in two categories of soft-tissue fillers: calcium hydroxylapatite and hyaluronic acid. Dermatol Surg 2010;36:1859-65.

14. Cohen JL. Understanding, avoiding and managing dermal filler complications. Dermatol Surg 2008;34:S92-99.

15. Shahrabi Farahani S, Sexton J, Stone JD, et al. Lip nodules caused by hyaluronic acid filler injection: report of three cases. Head Neck Pathol 2012;6:16-20.

16. Lowe NJ, Maxwell CA, Lowe $P$ et al. Hyaluronic acid skin filler: adverse reaction and skin testing. J Am Acad Dermatol 2001;45:930-3.

17. Lupton JR, Alster TS. Cutaneous hypersensitivity reaction to injectable hyaluronic acid gel. Dermatol Surg 2000;26:135-7.

18. Sage RJ, Chaffins ML, Kouba DJ. Granulomatous foreign body reaction to hyaluronic acid: report of a case after melolabial fold augmentation and review of management. Dermatol Sur. 2009;35:1 696-700.

19. Sanchis-Bielsa JM, Bagan JV, Poveda R, et al. Foreign body granulomatous reactions to cosmetic fillers: a clinical study of $\mathbf{1 5}$ cases. Oral Surg Oral Med Oral Pathol Oral Radiol Endod 2009;108:237-41.

20. Junkins-Hopkins JM. Filler complications. J Am Acad Dermatol 2010;63:703-5.

21. Raulin C, Greve B, Hartschuh W, et al. Exudative granulomatous reaction to hyaluronic acid (Hylaform). Contact Dermatitis 2000;43:178-9.

22. Monheit GD, Rohrich RJ. The nature of long-term fillers and the risk of complications. Dermatol Surg 2009;35:1598-604.

23. Grossman KL. Hyaluronic acid gel fillers: hypersensitivity reactions. Aesthet Surg J 2005;25:403-5.

24. Prigent-Combaret C, Vidal 0, Dorel C, et al. Abiotic surface sensing and biofilmdefendant regulation of gene expression in Escherichia coli. J Bacteriol 1999;181: 5993-6002.

25. Sclafani AP, Fagein S. Treatment of injectable soft tissue filler complications. Dermatol Surg 2009;35:1672-80.

26. Rohrich RJ, Monheit G, Nguyen AT, et al. Soft tissue filler complications: the impor- tant role of biofilms. Plast Reconstr Surg 2010;125:1250-6.

27. Alijotas-Reig J, Garcia-Gimenez V. Delayed immune-mediated adverse effects related to hyaluronic acid and acrylic hydrogel dermal fillers: clinical findings, long-term follow-up and review of the literature. J Eur Acad Dermatol Venereol 2008;22:150-61.

28. Stewart DB, Morganroth GS, Mooney MA, et al. Management of visible granulomas following periorbital injection of poly-Llactic acid. Ophthal Plast Reconstr Surg 2007;23:298-301.

29. Narins RS, Coleman $3^{\text {rd }}$ WP, Glogau RG. Recommendations and treatment options for nodules and other filler complications. Dermatol Surg 2009;35:1667-71.

30. Niamtu $3^{\text {rd }}$ J. Filler injection with microcannula instead of needles. Dermatol Surg 2009;35:2005-8.

31. DeFatta RJ, Krishna S, Williams $3^{\text {rd }}$ EF. Pulsed-dye laser for treating ecchymoses after facial cosmetic procedures. Arch Facial Plast Surg 2009;11:99-103.

32. Ellen SC, Adigun CG. Complication of injectable fillers and neurotoxins. Derm Therapy 2011;24:524-6.

33. Park TH, Yeo KK, Seo SW, et al. Clinical experience with complications of hand rejuvenation. J Plast Reconstr Aesthet Surg 2012;65:1627-31.

34. Kim DW, Yoon ES, Ji YH, et al. Vascular complications of hyaluronic acid fillers and the role of Hyaluronidase in management. J Plast Reconstr Aesthet Surg 2011;64:15905.

35. Brody HJ. Use of hyaluronidase in the treatment of granulomatous hyaluronic acid reaction or unwanted hyaluronic acid misplacement. Dermatol Surg 2005;31: 893-7.

36. Winslow CP. The management of dermal filler complications. Facial Plast Surg 2009;25:124-8.

37. Weidman MJ. Varioderm: a new generation of hyaluronic acid. Eur Dermatol 2008;4:50-3.

38. Huh SY, Cho S, Kim KH, et al. A case of complication after matridex® injection. Ann Dermatol 2010;22:81-4.

39. Klein AW. Granulomatous foreign body reaction against Hyaluronic acid. Dermatol Surg 2004;30:1070.

40. Bidic SM, Hatef DA, Rohrich RJ. Dorsal hand anatomy relevant to volumetric rejuvenation. Plast Reconstr Surg 2010;126: 163-8.

41. Soparkar CNS, Patrinely JR. Managing inflammatory reactions to Restylane. Ophthal Plast Reconstr Surg 2004;114:277. 